\title{
Pediatric Ophthalmology / Eye and Disorders
}

\author{
Hikmet Basmak, Nilgun Yildirim, Seyhan Topbas, \\ Ahmet Ozer, Nazmiye Erol, Huseyin Gursoy and Afsun Sahin \\ Eskisehir Osmangazi University Medical Faculty, \\ Department of Ophthalmology, \\ Turkey
}

\section{Introduction}

\subsection{Growth and development of child's eye}

The growth and development of eye harbors many challenging anatomical and physiological alterations starting from the intrauterine life until the early puberty. After the early puberty, the axial length of eye, which is defined as the anterior posterior diameter of the eye, remains unaltered in healthy subjects. However, the refractive status of the eye may still change in adults due to aging processes. The eye development starts in the 3-week embryo, from the optic vesicles. The eye is an organ which derives from all three of the germ layers (ectoderm, endoderm and mesoderm). The initial 3 years of life is the critical period for eye development, and rapid increase in dimensions of the organ takes place in these years. Clear vision is mandatory for the development of visual cortex in this critical period. It is accepted that normal adult visual capacity develops at 3 years of age (Fredrick, 2004).

The coordinated growth of eye's refractive components to reach a plano refraction is called emmetropization. If any failure happens in this process, refractive errors develop. The axial length is either too short, causing hypermetropia, or too long, causing myopia. Astigmatism is due to abnormal shapes in cornea. Very high degrees of hypermetropia (>5D) is not normal in newborns. The cornea and lens may flatten normally within years, but the axial length often pauses behind. This causes permanent hyperopia, which is called nanophthalmos. Generally, eyes with hyperopia of greater than 5 diopters have little chance of emmetropization (Mutti, 1992).

All anatomical alterations occur in order to achieve emmetropization. The corneal diameter at birth is about 9.5-10.5 $\mathrm{mm}$. The average adult size is $12 \mathrm{~mm}$. The corneal refractive power is 52 diopters at birth and 42-44 diopters in adulthood. Axial length is $17 \mathrm{~mm}$ at birth. It enlarges to $20 \mathrm{~mm}$ by the end of 12 months with continued rapid growth until 2 years old, then a slow increase to $24 \mathrm{~mm}$ by adulthood. The most rapid eye growth occurs within the first two years. At birth the power of the crystalline lens is 34 diopters. By 6 months of age power averages 28 diopters. By the adulthood the lens power reaches about 20 diopters. As cornea, lens, and axial length grow and change rapidly over the first months and years of life, the harmonization between these three components become crucial. 
Normal infant eyes are 2 diopters hyperopic. This increases slightly to around age 7, then decreases to age 9-12 years when emmetropia is reached. Normal eyes have diminutive refractive changes after 13 years (Mutti, 1992).

\section{Congenital eye anomalies}

The congenital eye anomalies may appear in isolation or as part of a systemic syndrome. It may be genetically proven in some cases. Either germ line or somatic mutations can cause eye abnormalities. They may result from disruption, deformation, intrauterine infection or teratogenic exposure. Some anomalies significantly affect visual acuity. On the other hand, there are some anomalies which are noticed incidentally on routine eye check with no significance to the patient (Kherani \& Robb, 2008).

\subsection{Infantile hemangiomas}

Infantile hemangiomas are the most common eyelid tumors in infancy. They have a bright red or purple appearance. Superficial ones typically blanch with pressure. At birth, they may be clinically undetected. However, they typically enlarge in the first 12 months followed by a slow involution during the first decade. Vision loss is related to amblyopia because of induced astigmatism or visual deprivation due to ptosis. Steroid treatment (intralesional and/or oral) is the first line of therapy (Levin, 2003).

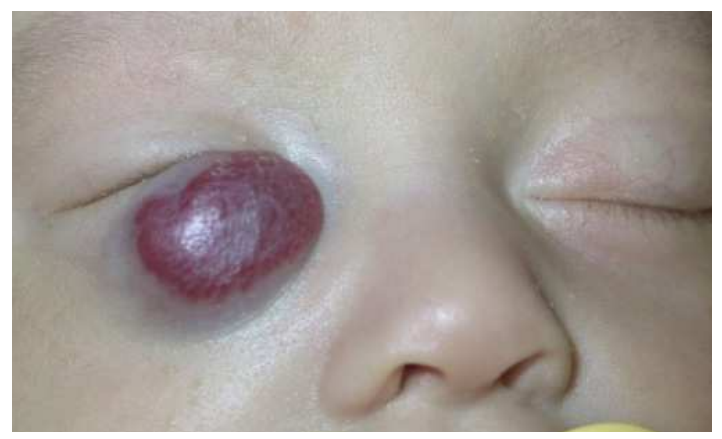

Fig. 1. Capillary hemangioma

\subsection{Epibulbar dermoids}

Choristomas (congenital dermoids) are masses of normal tissue found in an abnormal location. They induce astigmatism and cause refractive amblyopia. They may be excised to improve cosmetic appearance and avoid amblyopia.

\subsection{Microphthalmia}

A variety of disorders in which axial length is at least two standard deviations below normal is called microphthalmia. It is frequently associated with secondary orbital and ocular deformity including cataract and coloboma. It is frequently associated with various genetic conditions such as trisomy 13, Goldenhar's syndrome (Kherani \& Robb, 2008). 


\subsection{Colobomas}

It results from failure of the embryonic fissure to close along the inferonasal side of the optic cup during embryogenesis. It is frequently associated with microphthalmia. The visual prognosis is linked to the degree of optic nerve and macular involvement.

\subsection{Persistant fetal vasculature (persistant hyperplastic primary vitreus)}

It occurs sporadically and unilaterally in full-term health infants. The affected eye is microphthalmic with a shallow anterior chamber. A vascularized membrane behind the lens is typical. If the eye is not severely microphthalmic, surgical intervention may have a good prognosis (Levin, 2003).

\section{Optic nerve disease in children}

The optic nerve is approximately $50 \mathrm{~mm}$ long from the globe to the chiasm. It can be subdivided into four segments: Intraocular (optic disc, optic nerve head), intraorbital, intracanalicular and intracranial segment. Optic nerve is surrounded by the vascular pia, arachnoid and dura mater. The subarachnoid space is continuous with the cerebral subarachnoid space and contains the cerebrospinal fluid. The optic nerve carries approximately 1.2 million afferent nerve fibres which originate in the retinal ganglion cells (Kanski 2011).

Common congenital optic disc anomalies are present as follows: Tilted disc, optic disc pit, optic disc drusen (hyaline bodies), optic disc coloboma, morning glory anomaly, hypoplastic optic nerve and myelinated nerve fibres (Nicholson et al., 2011). Optic disc drusen is a common anomaly with a prevalence of $0.3 \%$ of the population. In buried drusen which are the most commonly encountered type, they mimic papilloedema. Exposed optic disc drusen are rare types and more easily diagnosed. They are usually innocent, but rarely may lead to visual field defects or optic disc neovascularisation. Ultrasound is important for the differential diagnosis by showing calcific deposits associated with drusen (Kanski 2011).

Optic neuritis is an inflammatory, infective or demyelinating process affecting the optic nerve. It can be classified both ophthalmoscopically and etiologically as follows. Papillitis is characterized by hyperemia and edema of the optic disc, associated with peripapillary flame-shaped hemorrhages. Neuroretinitis is characterized by papillitis in association with inflammation of the retinal nerve fibre layer and a macular star. The optic nerve head is normal in retrobulbar neuritis, because the optic nerve head is not involved. Optic neuritis may be seen due to demyelinating disease, parainfectious, infectious such as sinus-related, or associated with cat-scratch fever, syphilis, Lyme disease, cryptococcal meningitis and non-infectious such as sarcoidosis, systemic lupus erythematosus, polyarteritis nodosa and other vasculitides (Dale et al., 2009).

Papilloedema is swelling of the optic nerve head secondary to raised intracranial pressure. It is nearly always bilateral, although it may be asymmetrical. Systemic findings such as headaches, deterioration of consciousness, nausea and vomiting, may be seen in patients with papilloedema. Transient obscurations lasting a few seconds are frequent in 
patients with papilloedema. Horizontal diplopia due to 6th nerve palsy may accompany the clinical picture.

Optic nerve glioma is the most common primary neoplasm of the optic nerve. A low-grade form of this neoplasm, called benign optic glioma, occurs most often in the pediatric patients. On the other hand, the aggressive form of optic glioma, is most common in adults. Many children with optic nerve glioma are also known to have neurofibromatosis type 1 . Another optic nerve tumor is meningioma. Meningiomas are believed to arise from arachnoid cap cells, and they are usually attached to the dura.

Optic atrophy is the final common morphologic endpoint of any disease process that causes axonal degeneration in the optic nerve. There are two types; primary and secondary. Primary optic atrophy may be caused by lesions affecting the visual pathways from the retrolaminar portion of the optic nerve to the lateral geniculate body. Secondary optic atrophy is preceded by long-standing swelling of the optic nerve head.

\section{Retinitis pigmentosa}

Retinitis pigmentosa (RP) is a heterogeneous group of diffuse retinal dystrophies characterized by a progressive dysfunction affecting the rod more than the cone photoreceptors (a rod-cone dystrophy). It is the most common hereditary fundus distrophy with a prevalence of approximately 1:5000. All forms of RP can present in the first or second decade of life (Kanski, 2011).

\subsection{Inheritance and systemic associations}

$\mathrm{RP}$ can be inherited as an autosomal dominant (ADRP), autosomal recessive (ARRP) or Xlinked recessive (XLRP) pattern. RP can occur as an isolated sporadic disorder with no family history. The age of onset, rate of progression, eventual visual loss and associated ocular/systemic features are related to the type of inheritance (Khani, 2011). Approximately $20 \%$ of these cases are ADRP, and $6 \%$ to $9 \%$ are XLRP. The remaining $71 \%$ to $84 \%$ are either ARRP or isolated simplex cases. Up to $40 \%$ of recessive cases are associated with other systemic pathologies or syndromes and $18 \%$ have associated hearing loss. The most common forms of ADRP appear to have a later onset and less severe clinical course than XLRP. Significantly reduced visual function usually occurs at a younger age in XLRP than in other forms of RP. Most patients with XLRP are legally blind by age 30. Important systemic associations are Basen-Kornzweig syndrome (abetalipoproteinaemia), Refsum disease, Bardet- Biedl syndrome and Usher syndrome (Drack, 2006).

\subsection{Symptoms and diagnosis}

Typically patients present with night blindness and visual field constriction. Central vision may or may not be involved. Classical retinal signs include bone-spicule pigmentation, arteriolar narrowing and disc pallor. Cystoid macular edema may occur. The fundus may be normal in the early stages of disease and this is often the case in young children. Electroretinography (ERG) is essential in the workup of inherited retinal dystrophies. Bright flash scotopic ERGs show a reduced a-wave, indicating rod photoreceptor dysfunction with 
less severe photopic ERG abnormalities. Perimetry is useful in monitoring the progression of disease. Perimetry initially demonstrates small mid-peripheral scotomas that gradually coalesce to form the classical annular scooma that correlates in location and shape to the extent of fundus pathology (Kanski, 2011).

\subsection{Treatment}

Although the photoreceptor cell death of retinitis pigmentosa cannot at be arrested or reversed currently, some vision threatening complications (cataract and macular edema) can be successfully managed. Additional molecular and surgical therapies targeting various stages of the disease are under investigation. (gene and stem cell-based therapies, prosthetic retinal implants, germ and somatic cell gene replacement, allele-specific targeting strategies and retinal transplantation etc.)

\section{Retinopathy of prematurity}

Retinopathy of prematurity (ROP) is a disease of premature babies. The disease is a potentially blinding disorder affecting primarily the retinas of the premature infants. Three epidemics of ROP have been described. The first one was seen in the 1950s in the industrialized countries. The reason was uncontrolled oxygen therapy and inadequate neonatal intensive care. With developing technology in the western countries, the incidence of the surviving extremely low birth weight babies increased. This increase in survival resulted in another epidemic. This epidemic of ROP was the second epidemic, which was characterized by extremely low birth weight babies with ROP. Currently there is an ongoing epidemic in the third world countries. The characteristics of this third epidemic are the mixture of the first and second epidemics (Gilbert, 2008).

\subsection{Risk factors and pathogenesis}

Uncontrolled oxygen therapy and premature birth are the most important risk factors for ROP. Babies born at or before 31 weeks of gestational age, or weighing 1500 grams or less are under high risk for ROP. Systemic problems associated with prematurity may also be considered to be independent risk factors. Sepsis, anemia and growth retardation are the most significant of these systemic associations.

The retina is not completely vascularized at birth. Especially the temporal quadrant of the retina lack blood vessels in the neonates and the retinal vessels development continues until the end of the first month of age. Vascular endothelial growth factor (VEGF) is very important for the retinal vasculature development. If uncontrolled and high oxygen therapy is applied in a premature infant, the production of VEGF may increase resulting in the development of ROP. Under physiological conditions, VEGF production is stimulated by hypoxia. Therefore, it is not exactly known why high oxygen levels lead to increased VEGF levels. The possible explanation for this inconsistency is the high variations encountered during uncontrolled oxygen supply. High oxygen levels suppress VEGF initially. This is followed by an exaggerated VEGF production, after cessation of the oxygen therapy. To prevent such variations in oxygen blood levels, oxygen supply should be given in a more steady level, according to the needs of the infants. 


\subsection{Clinical presentation}

The ROP can be categorized as active and chronic disease. Active disease is the ROP diagnosed at the early months of infancy. Most of the cases regress spontaneously. The role of an ophthalmologist is to recognize the more severe cases with the risk of progression and to apply treatment in the indicated cases. Ridge formation in the periphery of the retina is a feature of early ROP. Ridge is a fibrovascular tissue, developed as a response to hypoxia. Retinal bleeding and/or tractional retinal detachment may occur, if the disease progresses.

In $20 \%$ of the babies with active ROP, chronic sequels of the disease may evolve. Most of these are innocuous, but fibrovascular tissues leading to macular distortion or retinal detachment may also develop. These may result in visual loss or even total blindness.

\subsection{Screening}

Screening by an ophthalmologist is recommended for infants with a birth-weight of $\leq 1500$ grams and/or $\leq 31$ weeks of gestation. The time for screening is 4-7 weeks postnatally. There is inconsistency in the literature regarding the screening protocols. Protocols including more mature babies may be designed for developing countries (Basmak, 2009).

\subsection{Management}

Argon laser photocoagulation is performed in babies with threshold disease. Threshold disease is defined as 5 contiguous clock hours or 8 total clock hours of extraretinal neovascularisation located at or near the macula, which is the critical region of the retina for vision. Plus disease is also a feature of the threshold disease. It is defined as sausage like dilatations of the vessels around the optic disc, as a response to hypoxia. Posterior segment surgeries are indicated if retinal detachment occurs. The outcomes after laser therapy are successful in $85 \%$ of the cases, but they are not promising after surgery. Laser ablation of the avascular retina is applied to halt the progression of ROP. VEGF inhibitors alone or combined with laser therapy or surgery may be injected into the eyes to stop or slow the progression of the disease (Erol, 2011).

Pediatricians must be aware of the association between refractive disorders, amblyopia and strabismus in early or late childhood period and ROP. The risk of developing these disorders is correlated with the severity of ROP, but it still exists in regressed ROP cases with no sequel according to some literature. Therefore all ROP cases must be routinely referred to an ophthalmologist to screen for these possible associations.

\section{Lacrimal system disorders in children}

Unlike many insidious and asymptomatic ocular pathologies in children lacrimal system disorders alert parents immediately, because of an obvious watering eye with adherence of the lashes and with a mucoid discharge. Congenital nasolacrimal duct obstruction is the main etiology of epiphora in the pediatric age group.

\subsection{Congenital nasolacrimal duct obstruction}

The nasolacrimal duct is the continuation of the lacrimal sac. It opens into the nasal meatus. Its final end is partially covered by a mucosal fold called the valve of Hasner. This final 
lower part of the canal at the level of the valve of Hasner, is not completely developed in some of the neonates. This developmental delay present in one fifth of the neonates. Spontaneous resolution of epiphora occurs in more than $90 \%$ of the cases within a year, after completion of the lower end of the canal (Ballard, 2000).

\subsection{Differential diagnosis of epiphora in children}

Amniontocele (congenital dacryocele), punctual atresia or fistulae between the sac and the skin are other rare etiologies for epiphora. Amniotecele is characterized by a blue-green distention of the lacrimal sac, observed externally at the level of inner canthus. It is due to an imperforate valve of Hasner. Amniontocele is mostly self limiting within a few days of birth, especially if massage is applied (Rose, 2000).

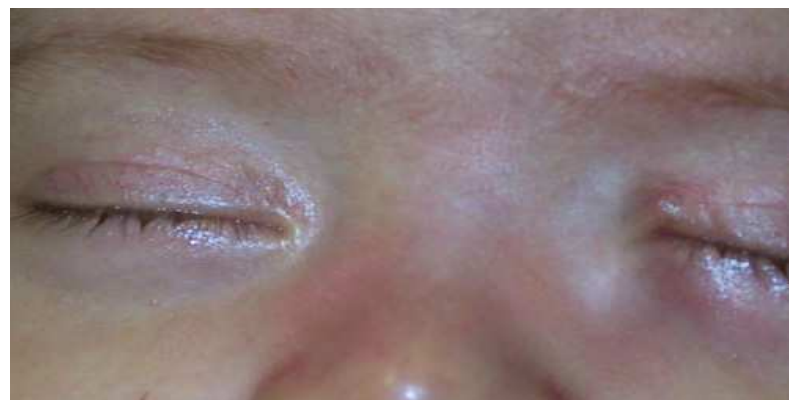

Fig. 2. Left dacryocele

\subsection{Management of congenital nasolacrimal duct obstruction}

Spontaneous resolution is usual, so conservative treatments including antibiotic drops and massage of the lacrimal sac region is preferred within the first year of life. The index finger is put over the inner canthal region and the massage is applied firmly downwards. Three strokes of massage, 3-4 times per day are recommended. Early intervention is indicated if recurrent dacryocystitis occur before the first year of age.

Probing of the nasolacrimal canal under general anesthesia is performed if epiphora persists beyond the first year of age. Probing is performed to disrupt the obstructive membrane at the level of valve of Hasner mechanically. The success rate of probing is very high. If it fails, the probing can be repeated once more. If epiphora persists after 2 technically satisfactory probing, more invasive procedures, including silicon tubes implantation, balloon dilatation of the nasolacrimal duct or dacryocystorhinostomy should be considered (Rose, 2000).

Dacryocystorhinostomy is an invasive surgery, which involves anastomosing the lacrimal sac to the middle meatus by the removal of the lacrimal bone, is the gold standard treatment in adults, whereas it is usually the final treatment alternative in the pediatric age group.

\section{Childhood cataract}

The lens is a biconvex structure that hangs behind the iris. Its diameter is about $3.5 \mathrm{~mm}$ at birth and it grows to about $10 \mathrm{~mm}$ by adulthood. There are three structural elements that 
constitute the lens: capsule, epithelium and fibers. The crystalline lens is a transparent structure that helps to refract light to be focused on the retina, along with the cornea. The lens is capable of changing its shape in order to modify the focal distance of the eye, so that it can focus on objects at different distances, thus allowing a clear image of the object to be formed on the retina (Kanski, 2011).

Cataract is the opacification of the crystalline lens. Cataracts result from protein denaturation, increased molecular weight of proteins, water vesicles between lens fibers, increasing proliferation and migration of the lens epithelium. Childhood cataract occurs worldwide and is an important cause of childhood blindness in many countries. Congenital cataracts occur in about 3 in 10000 live births. Two-thirds of cases are bilateral. The cause of the cataract can be identified in about half of the cataractous eyes. Unilateral cataracts are usually isolated sporadic incidents, without a family history or systemic disease and effected infants are usually full-term and healthy. Cataract can be associated with ocular abnormalities, trauma, or an intrauterine infection such as rubella. Bilateral cataracts are often inherited and associated with other diseases. They require a full metabolic, infectious, systemic and genetic workup. The common causes are hypoglycemia, trisomy (eg, Down, Edward and Patau syndromes), myotonic dystrophy, infectious diseases (eg, toxoplasmosis, rubella, cytomegalovirus and herpes simplex [TORCH]) and prematurity. Isolated hereditary cataracts account for about $25 \%$ of the cases. The mode is most frequently autosomal dominant, but may be autosomal recessive or X-linked (Mickler, 2011).

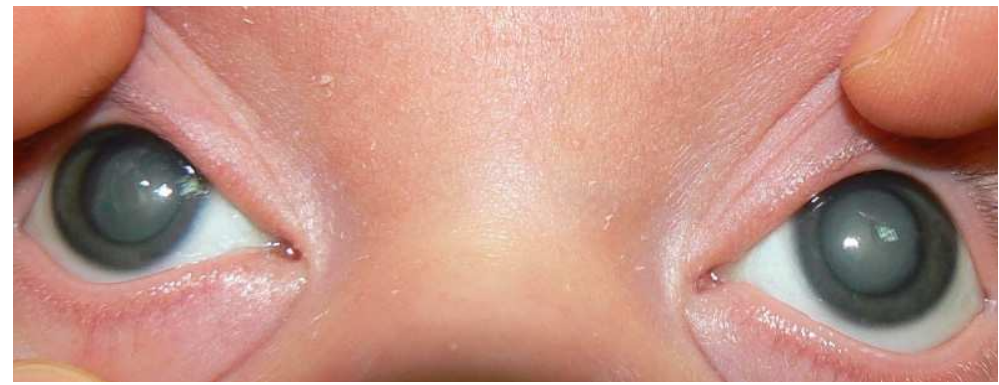

Fig. 3. Bilateral conjenital cataract

Detailed eye examination is required for the density and morphology of the any lens opacity. Potential impact on visual function of cataract is assessed on the basis of the appearance of the red reflex and the quality of the fundus view on direct and indirect ophthalmoscopy. A very dense cataract occluding the pupil will preclude any view of the fundus. In case of pediatric cataract serology should be done for intrauterine infections. Urinalysis for reducing substance after drinking milk (galactosaemia) and chromatography for amino acids (Lowe syndrome) should be performed. Other investigations include fasting blood glucose, serum calcium and phosphorus and galactokinase levels. Children who have calcium and phosphorus anomalies severe enough to cause cataracts are usually having associated severe systemic problems. Referral to a pediatrician may be warranted for dysmorphic features or suspicion of other systemic diseases. Chromosome analysis may be useful in this context. It is important to examine parents and siblings to reveal a possible etiology (Krishnamurthy \& Vanderveen, 2008). 
Dense cataracts require early surgery when the child is 4-6 weeks of age to prevent the development of stimulus deprivation amblyopia. If the severity is asymmetrical in bilateral cataracts, the eye with the denser cataract should be addressed first. Surgery may not require in partial cataracts if opacity is not central.

\section{Childhood glaucoma}

The exact definition of glaucoma is still a subject of debate. What that did not change over years is that raised intraocular pressure is the most important risk factor for glaucoma development. Glaucoma is generally the disease of adults, occurring most frequently over 40 years of age. However, it may also develop in children.

Primary congenital glaucoma (PCG) is the most common reason for raised intraocular pressure in child. It occurs in 1:10000 births and more commonly in boys. 75\% of the cases are bilateral. Although autosomal recessive cases have been described, most cases of PCG are sporadic. Glaucoma develops due to the anomalous development of the anterior chamber angle. Raised intraocular pressure, cloudy cornea, large appearance of the eye (buphthalmos), optic nerve alterations due to high intraocular pressure and special biomicroscopic signs are diagnostic features of PCG.

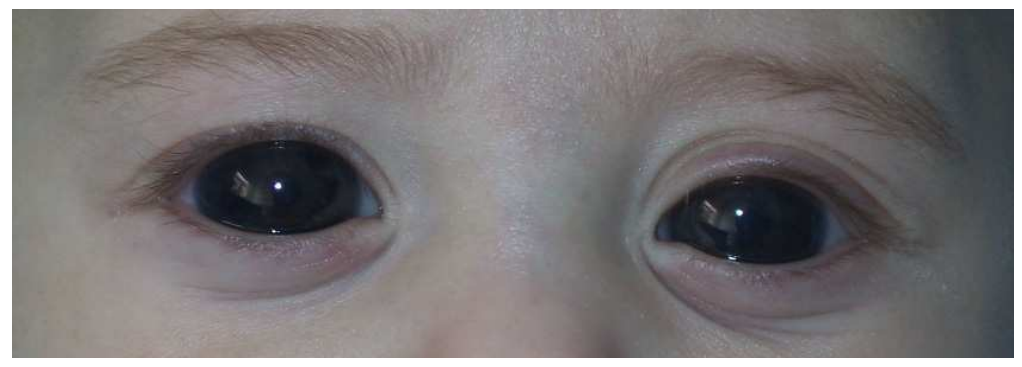

Fig. 4. Buphthalmos in PCG

PCG has 3 subtypes; true, infantile and juvenile PCG. Intraocular pressure is elevated during intrauterine life in true PCG, whereas the disease started before 3 years of age in infantile PCG. Infantile cases are the most frequently encountered ones. Treatment is surgical in all cases of PCG. Medications may also be used concomitant with the surgery. The initial evaluation must be performed under general anaesthesia. Enlargement of the eye in pediatric age group should be referred to an ophthalmologist (Idrees, 2006).

\section{Pediatric eye examination}

There is no consensus on when the initial eye examination in a healthy child should be performed and how often the examinations should be repeated in the presence of normal eyes. Premature infants at risk of retinopathy of prematurity must be screened by an ophthalmologist. Many congenital ocular abnormalities may be diagnosed by simple observation by a pediatrician, if they are aware of the possible congenital ocular diseases.

In developed countries, the initial eye examination by an ophthalmologist is commonly performed at 6 months of age. At this age, the alignment of the eyes and the near focussing 
of the infant can be checked. An infant should be able to fix and follow faces within 2-3 weeks of age (Allen, 2000). The ability of the young children to fixate and follow a small target is an important gross evaluation of vision. Consistent objection from the child to having one eye occluded suggests that the un-occluded eye is amblyopic. Refraction examination and the red reflex test should be performed. The red reflex test is a screening test for retinal abnormalities and opacities in the visual axis such as congenital cataract and corneal opacities. It is performed by focusing an ophthalmoscope light from $30 \mathrm{~cm}$ away from the child's eyes. If the red reflex of the 2 eyes is symmetrical, the test is normal. Dark spots in the red reflex or leukocoria (white reflex instead of red reflex) are indications for referral to an ophthalmologist.

Special tests to confirm that, an infant sees, may be performed. Optokinetic drum test and the spinning test are the most popular simple methods to confirm visual response in an infant. Forced choice preferential looking is a popular way of quantifying infant vision. Portable cards; namely Teller or Keeler cards are used to quantify infant vision. Optotype tests to quantify visual acuity may be used in children between 1-3 years of age. Cardiff acuity cards at 1-2 years of age and Sheridan Gardner optotypes at 2-3 years of age are the most commonly preferred ones. In children over 3 years of age, Snellen acuity charts may be used. Eye movements and the position of the eyes should be simply observed. Hirschberg test, which is a light reflex test, is used to exclude manifest eye deviations. If an infant with manifest deviation fixates the penlight, the corneal reflex will be eccentric in the deviating eye. The reflex will be displaced nasally in the exotropia, and temporally in the esotropia.

Pupils are smaller and poorly reacting in the newborns. Normal pupillary reactions should be documented by 3 months of age. Iris colour is permanent at 1 year of age. Colour vision assessment can be performed by the Hardy-Rand- Rittler plates in children as young as 3 years of age (Mollon et al., 1991). If the child cannot tolerate ophthalmic examination and detailed examination is indicated, sedation can be required. Routine intraocular pressure measurement in cases with congenital glaucoma is an example for such conditions.

Eye examinations after 3 years of age are more informative and more easily performed. Visual acuity assessment and the fundamental parts of eye examinations are similar with the adult patients. However, the physicians should keep in mind that, refractive status of the eye is very dynamic in preschool and school children, and preschool vision screening is recommended for all children.

\section{Refractive disorders}

\subsection{Definitions}

Ametropia, which is defined as the presence of any of the refractive disorders, is the most commonly diagnosed disorder of the human eye. Ametropia includes the hyperopia, myopia and astigmatism. The most common refractive error in the pediatric population is myopia. The World Health Organisation estimates refractive disorders to be $2-10 \%$ worldwide. The prevalence is found to be much higher in the Far East. The prevalence of astigmatism of 1 diopter or more is $50 \%$ in infancy. The prevalence decreases rapidly during the process of emmetropization. Only few children develop astigmatism greater than 1 diopter by 6 years of age (Maida et al., 2008). 


\subsection{Etiology}

The total refractive power of the human eye is approximately 60 diopters (D). The cornea provides two thirds of this total power and the lens provides the remaining $20 \mathrm{D}$. The normal eye creates clear images by focusing the images on the retina. If the unaccommodated eye focuses the images behind the retina, hperopia (farsightedness) develops. On the other hand myopia (nearsightedness) is the state in which the unaccommodated eye focuses the images in front of the retina. The hyperopia and myopia may be due to altered total refractive power of the eye, but the axial length changes instead of that is the most common reason in most of the cases. Reduced axial length results in hyerpopia and the reverse in myopia (Riordan-Eva, 2004).

The parental history of myopia, genetic predisposition and various environmental factors are associated with the development of myopia in a child. Familial predisposition also exists in hyperopia, which is much less common in the pediatric population. The children can tolerate low amounts of hyperopia by accommodation, so most of the low amounts of hyperopia are unrecognized in this population. However, higher degrees may result in amblyopia and should be corrected promptly.

A healthy eye is able to focus all the light rays from a point source to a single point. In the presence of astigmatism, this focusing process to a single point is disrupted due to variations in the curvature of the cornea or lens at different meridians. Most of the astigmatisms are the consequences of alterations in corneal curvatures. In other words, the refractive power of some part of the cornea is higher or lower than the rest of the cornea, so the astigmatism results. If these regions of the cornea with different refractive power capacity are 90 degrees apart, the astigmatism is regular. If these regions are not 90 degrees apart, it is called irregular. Keratoconus is an important reason for irregular astigmatism.

\subsection{Management}

Spectacles, contact lenses, refractive surgery, intraocular lenses and clear lens extraction are the current methods of refractive correction. Refractive disorders place a significant economic and social burden on society. In USA, $\$ 4.6$ billion was spent for treatment of myopia in 1990. Spectacles continue to be the safest method of correction, whereas the interventional procedures are very rarely preferred in the pediatric population. Anisometropia refers to a difference in the refractive status of the 2 eyes. If the difference is 2 diopters or more, either spherical or astigmatic, it is clinically significant. Anisometropia should be managed with caution, since it is the most important risk factor for amblyopia.

\section{Amblyopia}

\subsection{Definition}

A physician must be aware of the definition of amblyopia properly to understand the importance of early diagnosis and management of amblyopia. Amblyopia is the combination of two Greek words; amblyos - blunt and opia -vision. The parents commonly 
use the lazy eye terminology instead of ambloypia. Due to the suppression of the blurred vision from the diseased eye, the risk of development of unilateral amblyopia is much higher than the risk of bilateral amblyopia. However, it may also develop bilaterally, if severe visual deprivation occurs in both eyes. A same ocular pathology that develops in a child may be an important etiology for a severe amblyopia, while the same pathology in the elderly decreases the visual acuity, but does not result in an amblyopia. This is very typical for the lens pathologies. Congenital cataracts are one of the important etiologies for amblyopia, while senile cataracts are the most common treatable cause of vision loss among the elderly. Any pathology that results in abnormal visual experience in one or two eyes before the critical period of visual development may result in amblyopia. The critical period usually ends at 6-8 years of age (Morishita, \& Hensch, 2008). The amblyopia is the disease of the visual cortex and it only develops in children younger than $6-8$ years old. The critical period is the time of maximum neurological plasticity of the visual cortex cells. The visual acuity and binocular vision improves depending on the visual inputs until the end of the critical period. There is no consensus on which visual acuity should be adopted for the clinical definition of amblyopia. The cut-off level varies between 20/40 and 20/30 and the prevalence also varies accordingly. The prevalence of the disease may be considered approximately $2 \%$ in the general population (Webber \& Wood, 2005).

\subsection{Etiology}

There are many treatable and untreatable causes of amblyopia. The most common etiologies are eye deviations and refractive errors. Anisometropia is a significant difference in the refractive status between the two eyes. The eye with more hypermetropia or more astigmatism is chronically blurred, so the risk of the development of amblyopia is high in that eye. Congenital cataracts, retinoblastoma, nystagmus, corneal opacities and any ocular media opacities including vitreous hemorrhages may end up with amblyopia, if they occur before the critical period of visual development (Carlton \& Kaltenthaler, 2011).

\subsection{Management}

The severity of the amblyopia depends on the severity of the blur, the duration of the abnormal vision and the age of onset of the visual impairment. The pediatrician plays a crucial role in the early diagnosis of possible causes of amblyopia. The major determinants of success in amblyopia treatment are early recognition by the pediatrician, early referral to the pediatric ophthalmologist and prompt treatment.

The initial step in the management is the correction of the underlying etiology, if possible. Surgical treatment of the strabismus, or the congenital cataract, correction of the refractive errors by glasses or contact lenses are the main treatment modalities for the correction of the most common causes of amblyopia. In some pathologies, such as nystagmus, retinoblastoma, it is not possible to eliminate the underlying cause of blurred vision totally. Therefore, the management of amblyopia due to such untreatable diseases is very difficult.

After the correction of the underlying organic pathology, the most difficult aspect of the management starts; the occlusion of the sound eye in most cases or the alternate occlusion if the condition is bilateral. The aim of the patching the diseased eye is to improve the visual 
cortex which receives the inputs from the bad eye. This is possible if the neurological plasticity of the visual cortex remains. The best outcomes are achieved if the management starts before 5 years of age, but the patching may be tried up to 22 years of age (Matta et al., 2010). If children cannot tolerate patching, the penalization, which is the impairment of vision in the sound eye by eye drops, can be preferred. There is no consensus on the duration of patching per day and the total duration of the treatment. However, it is known that, it is long treatment frequently lasting more than years. Well cooperation with the parents is crucial to obtain successful outcomes. It is commonly accepted that amblyopia cannot be treated beyond a certain age. However, some trials to manage amblyopia in adults gave promising results. Perceptual visual learning and levodepo are the possible new treatment modalities for amblyopia in the elderly. These may also be tried in elder children, if conventional treatments fail (Astle et al., 2011).

\section{Pediatric eye deviations}

Under normal physiological conditions, the image of an object falls simultaneously on the fovea of each. This is possible if the eyes are properly aligned. This straight position of the eyes is called orthophoria. Any misalignment of the either eye is called strabismus or eye deviation in other words. There are 2 benefits of treating strabismus. The initial one is functional gain including the improvement of visual acuity and stereopsis. The second one is the cosmetic improvement.

\subsection{Types of eye deviations}

Tropia defines manifest deviation of eyes and phoria implies latent deviation. Phoria is detected by the simple cover-uncover test. The test is performed while the patient fixates a distant object. The physician covers one eye for 2-3 seconds and then the other eye. If orthophoria is present, no movement is detected. If latent deviation exists movement of eyes towards the opposite of the deviation is observed. For example in a patient with inward latent deviation, the uncovered eye move from inwards to outwards. Latent deviations may become manifest temporarily, when the child is tired or ill. It can also become permanently manifest during the follow-up.

Horizontal deviations are the most commonly observed types of strabismus. Esotropia is the manifest inward deviation of eyes, while esophoria is the latent inward deviation of eyes. Exotropia is the manifest outward deviation of eyes, while exophoria is the latent outward deviation of eyes. Esotropia is by far the most common form of strabismus. Infantile esotropia constitutes almost half of all cases of esotropia. Infantile esotropia is the inward deviation of eyes, which is diagnosed at 6 months of age. The angle of deviation is usually large and surgery is usually indicated. Pseudo-strabismus is the illusion of deviation in a child with orthophoria. It is most commonly in the form of pseudo-esotropia. The most common reason for this false appearance of inward deviation is broad nasal bridge with prominent epicanthal folds. This appearance usually resolves spontaneously and requires no treatment (Fredrick, \& Asbury, 2004).

Paralytic strabismus in children may be in form of third, fourth or sixth cranial nerve palsy. 
The most common one is the sixth cranial nerve palsy (abducens palsy), which is characterized by loss of abduction. Cranial imaging must be ordered in all forms of acquired paralytic strabismus to exclude cranial masses (Harley, 1980).

The angle of deviation in eyes with all types of deviations is measured objectively by using special prisms. The prism cover test is preferred if the child cooperates. In severe amblyopia and in very young children prism reflex test (Krimsky test) is performed. The patient fixates a light and the prism is placed in front of the deviating or bad eye to center the corneal reflex.

\subsection{Management}

Associated amblyopia and refractive errors must be addressed initially in all cases of strabismus. Abnormal eye movements are frequently associated with pediatric eye deviations and they can influence the management of the cases. Accommodative types of esotropias may be completely cured with spectacles. Surgical correction is decided according to the angle of deviation, if the deviation is not corrected by the spectacles during follow-up. All types of strabismus must be referred to an ophthalmologist, since early treatment by spectacles or surgery is important for normal binocular visual development.

\section{Common eyelid and orbital diseases in children}

The most important issue in pediatric eyelid disorders is to identify whether the lesions affect the visual development or not. If it occludes the visual axis, the pathology must be treated promptly to prevent the development of amblyopia. Entropion, ectropion, distichiasis, epicanthal folds, and telecanthus (increased distance between the medial canthus of each eye) are common congenital anomalies of the eyelids. Although they are solely cosmetic problems in most cases, they may result in corneal changes secondary to corneal irritation and exposure due to mal-position of the eyelids.

Congenital ptosis is the most important disease of the eyelids in a child. It is usually unilateral and occurs sporadically in most cases. The underlying pathology is the dysplasia of the levator palpebralis muscle. Surgical correction during the preschool years must be performed. If the disease is severe, early surgery to prevent amblyopia may be performed.

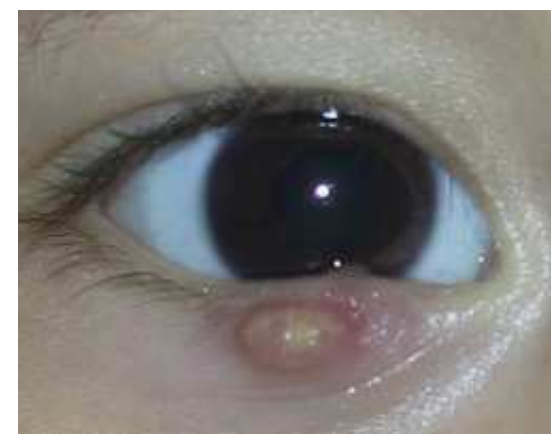

Fig. 5. Stye at lower eyelid 
Chalazion (Chronic inflammation of the meibomian glands), blepharitis (effects base of the eyelashes) and acute infection of the eye lash follicle (stye) are very frequent infections of the eyelids in children. The infections are mostly innocent and respond well to conservative therapies (Hughes, 2000).

\subsection{Orbital infections}

The bacterial infections of the soft tissue anterior or posterior to the orbital septum are the most common diseases of the orbit in the pediatric age group. The infections occur in two clinical forms; preseptal cellulitis or orbital cellulitis. Orbital cellulitis is the most common cause of protrusion of the eyeball in children. It is a life-threatening disease of the tissues behind the orbital septum. On the other hand, preseptal cellulits involves tissues anterior to the orbital septum. Preseptal cellulitis usually responds to ampiric antibiotic treatment, whereas orbital cellulitis may be associated with serious complications requiring longer periods of treatment and surgical interventions (Kanski, 2011).

Protrusion of the eyeball, limitations of the eye movements and decreased visual acuity are signs of orbital cellulitis. Skin trauma, sinusitis, lacrimal sac infections and rarely remote infections may be the source of preseptal or orbital cellulitis. Preseptal cellulitis rarely progresses to orbital cellulitis.

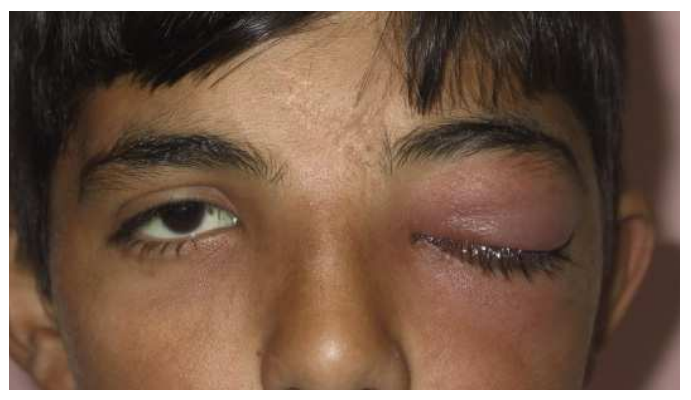

Fig. 6. Left orbital cellulitis

Subperiosteal and orbital abscesses, intracranial complications (meningitis, brain abscess) and ocular complications such as optic neuropathy and endophthalmitis may complicate orbital cellulitis. Hospitalization and aggressive medical treatment to prevent lifethreatening complications is indicated in orbital cellulitis (Sullivan, 2004). Any painful periorbital edema or pain associated with eye movements should raise the suspicion of serious orbital cellulitis and referral to an ophthalmologist is indicated.

\section{Conjunctival diseases in children}

\subsection{Ophthalmia neonatarum}

Ophthalmia neonataurum means, conjunctivitis occurring in the first month of life. It is still a significant cause of blindness in underdeveloped countries. It can be bacterial, viral and chemical. The most serious form is caused by Neisseria gonorrhoeae. Onset is typically within the first 3-4 days of life. It causes a severe purulent discharge. Treatment includes systemic 
ceftriaxone and topical penicillin as well. Infection with herpes is rarer but requires prompt therapy with acyclovir. Chemical cases are caused by silver nitrate and occur within 24 hours life. Tetracyclin, erythromyicin ointments or povidone-ioidine drops can be used for prophylaxis.

\subsubsection{Conjunctivitis}

Conjunctivitis in children is one of the most common reasons to visit a pediatrician. Majority of these infections are self-limited and does not require therapy. This section covers a variety of infectious conjunctival diseases that might be confronted in routine pediatrics practice.

Red eye is one of the most important ophthalmological emergencies. There are several causes such as conjunctivitis, keratitis, uveitis etc. Fortunately, majority of the red eye occurs due to conjunctivitis. The underlying etiology is almost always bacterial in children. However, it can be viral or allergic. During examination there are some key points that will help to differentiate the etiology:

Symptoms: Allergic cases will always have prominent itching. Bacterial cases will always have discharge.

Presence and nature of discharge: Bacterial infections will have a purulent, yellow-green discharge. Viral cases will have a serous or mucoid discharge. Allergic cases will have serous discharge with excessive tearing.

Laterality: Bacterial cases can be either unilateral or bilateral. Viral and allergic conjunctivitis occur almost always bilateral.

Cul-de-sac: Always pull the lower eyelid away from the globe to examine the cul-de-sac. Bacterial conjunctivitis will have tarsal papillae. Viral and allergic conjunctivitis will have tarsal follicles.

Systemic associations: Viral conjunctivitis might be associated with upper respiratory infections. Allergic conjunctivitis might be seen with upper respiratory allergic symptoms.

First-line therapy for bacterial conjunctivitis is topical flouroquinolone. In many cases polysporin, erythromycin or trimethoprim/sulfa is effective. Viral conjunctivitis is selflimited. For allergic cases topical antihistaminic drops are effective.

\section{Corneal diseases in children}

The cornea is the anterior transparent, avascular anatomical structure of the human eye. It constitutes $2 / 3$ of the total refractive capacity. There are many congenital and acquired corneal diseases, which may lead to blindness if left untreated. Corneal dystrophies, congenital anomalies, corneal ectasias, metabolic keratopathies and infectious diseases are the main corneal diseases that may be diagnosed in a child. Most of the corneal pathologies disturb the transparency of the organ and should be referred to an ophthalmologist immediately. Microcornea, megalocornea, anophthalmos and microphthalmos are rare congenital anomalies that affect cornea. Microphthalmos is defined as the developmental arrest of all ocular structures, while anophthalmos is the complete failure of the eye development. 
Corneal involvement (corneal edema, infiltrations or erosions) may be seen in cystinosis, mucopolysaccharidoses, Wilson disease, Fabry disease and tyrosinaemia type 2. The treatment of the systemic disease is the mainstay treatment of these metabolic keratopathies.

Corneal dystrophies and corneal ectasias are frequently diagnosed during puberty or later. They are structural diseases of the cornea and mostly genetically determined, but the clinical picture rarely occurs in childhood. Keratoconus is the most common corneal ectasia of the human eye. It is typically diagnosed during puberty with unilateral impairment of vision. Corneal thinning and irregular astigmatism are the main features of the keratoconus. Hard contact lenses and corneal transplantation are treatment options based on the severity of the disease (Ciralsky \& Colby, 2007).

\subsection{Keratitis}

Staphylococcus aeurus, staphylococcus epidermidis, and streptococcus pneumonia are the most common organisms that cause infectious keratitis. Bacterial keratitis usually occurs in patients with damaged corneal epithelial integrity. However, Neisseria gonorrhoeae, Corynebacterium diphteriae, Listeria and Haemophilus species may lead to keratitis in the presence of intact epithelium. Bacterial keratitis is characterized by oval shaped corneal infiltrations surrounded by corneal edema, conjunctival hyperemia (injection), ocular pain and photophobia.

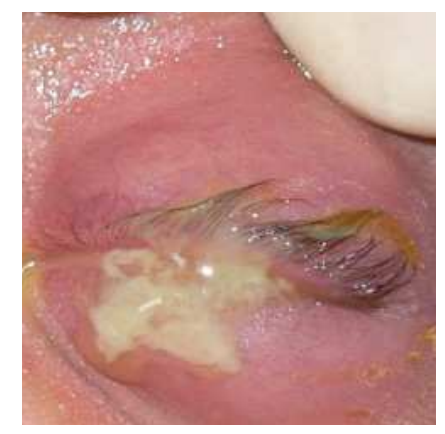

Fig. 7. Gonococcal keratoconjunctivitis

Pseudomonas aeruginosa keratitis tend be very severe and typically produces stromal necrosis with a shaggy surface and adherent mucopurulent exudates. It is an infection usually seen in contact lens users with a damaged corneal epithelial surface. The infection may progress rapidly ending with corneal perforation. In the management of keratitis, ampiric broad-spectrum therapy is recommended until the offending microorganism is identified in the culture. If the type of bacteria is identified from the stained diagnostic smear, then appropriate single drug therapy may be considered.

Herpes simplex virus (HSV) infection is more commonly acquired in adolescence than in childhood. It can be transmitted to neonates as they pass through the birth canal of a mother with genital infection that can lead to serious systemic disorders in the newborns. Primary ocular HSV infection is a form of HSV infection that typically manifests in children aged between 6 months and 5 years. It causes unilateral blepharoconjunctivitis that has signs such 
as cutaneous or eyelid marginal vesicles, or ulcers on the bulbar conjunctiva that can be rarely accompanied by dendritic epithelial keratitis. Primary ocular HSV infection is a self limited disease that usually resolves spontaneously. Oral antiviral therapy can speed up the resolution.

Dendritic ulcers, stromal necrotizing keratitis and disciform keratitis are forms of recurrent ocular infection of HSV. These may also occur in this age group. Topical and oral antiviral therapy can be used in the management of recurrent HSV keratitis.

Adenoviruses are the most common viral pathogens that may cause viral keratitis in a child. Pharyngoconjunctival fever (PCF) and epidemic keratoconjunctivitis (EPC) are 2 different clinical pictures that are caused by different serotypes of adenoviruses. PCF is caused by types 3, 4 and 7, while EPC is caused by types 8, 19 and 37. Corneal involvement is much more common and severe in EPC. Keratitis may persist for years in some cases. PCF is the less severe form of the disease. Keratitis is usually mild and self limiting. Mild to moderate fever may accompany PCF. The management of adenoviral keratitis is usually conservative. Topical steroids and cyclosporine may be tried to reduce inflammation. Reduction of transmission risk by avoiding contact with infected patients during the initial 7-10 days of the active disease and by good hygiene is much more important than its management. Ophthalmologists are well experienced about EKC, because unfortunately the eye clinics are usually the most common places to come in contact with the adenovirus and many ophthalmologists are infected once or more with adenoviruses. Many outbreaks occur due to improperly disinfected diagnostic instruments (Kanski, 2011).

\subsection{Allergic diseases affecting the cornea}

Vernal keratoconjunctivitis is an allergic eye disease that is mainly seen in male children. Symptoms include itching, photophobia, and mucoid discharge. Corneal findings consist of Horner-Trantas dots (degenerated eosinophils and epithelial cells) in the limbal area, punctate epithelial erosions and shield ulcer (an oval noninfectious epithelial ulcer). Corneal findings are generally accompanied by conjunctival ones which are hyperemia, conjunctival edema (chemosis) and papillary hypertrophy. Topical antihistamines and mast-cell stabilizers can be used in the management of vernal conjunctivitis. Severe cases may require topical corticosteroid or topical immune-modulating agents such as cyclosporine.

Atopic keratoconjunctivitis is a rare bilateral allergic eye disease that is most commonly diagnosed in young men, but also in children. Clinical picture is similar to vernal keratoconjunctivitis, but more severe. The papillary hypertrophy are less developed compared to vernal keratoconjunctivitis. The history of allergy such as allergic asthma or atopic dermatitis is commonly associated. Keratopathy leading to total corneal neovascularization may occur. Management is similar to vernalis keratoconjunctivitis, but the disease is less responsive.

\subsection{Reiter syndrome}

It is characterized by the ocular triad (conjunctivitis/ episcleritis, iridocyclitis, or keratitis), urethritis and arthritis. It is usually associated with gram-negative bacterial ( Salmonella, 
Shigella and Yersinia) dysentery. Corneal diseases usually respond to topical corticosteroids (Kanski, 2011).

\section{Pediatric uveitis}

The uvea is a pigmented structure that primarily lies between the retina and the sclera and constitutes the vascular portion of the eye. It comprises the iris, ciliary body and choroid. Uveitis, by strict definition implies an inflammation of the uveal tract. Uveitis is named according to the anatomical location of inflammation in the uvea. Anterior uveitis may be subdivided into: Iritis and iridocyclitis. Iritis is primarily the inflammation of the iris tissue. On the other hand, iridocyclitis involves both the iris and the pars plicata of the ciliary body. Intermediate uveitis is defined as inflammation predominantly involving the pars plana, the peripheral retina and the vitreous. Posterior uveitis involves the fundus posterior to the vitreous base. Panuveitis implies involvement of the entire uveal tract without a predominant site of inflammation (Kanski, 2011).

Pediatric uveitis may be categorized into 4 types of uveitis based on the anatomical location of the inflammatory process. These are anterior (non-granulomatous and granulomatous), intermediate and posterior uveitis. Etiologic factors associated with these uvetis in children are as follows.

Anterior non-granulomatous uveitis: Idiopathic, HLA-B27 associated, juvenile rheumatoid arthritis (JRA), ankylosing spondylitis, Reiter's disease, psoriasis, inflammatory bowel disease, nephritis, systemic lupus erythematosus, Herpes Simplex virus (HSV), Lyme disease, leukemia, drug-induced.

Anterior granulomatous uveitis: Sarcoidosis, inflammatory bowel disease, syphilis, Herpes simplex virus, tuberculosis, Behcet's disease, multiple sclerosis, fungal disease, Whipple's disease, leprosy.

Intermediate uveitis: JRA, Pars Planitis, Multiple Sclerosis, Lyme disease, Sarcoidosis.

Posterior Uveitis: Toxocariasis, Toxoplasmosis, Leukemia, Tuberculosis, Intraocular Foreign Body, Vogt-Koyanagi Harada Syndrome (VKH), Cytomegalovirus, HSV/VZV, inflammatory bowel disease, syphilis, Behcet's disease, systemic lupus erythematosus, Kawasaki's disease, sarcoidosis, polyarteritis nodosa, Wegener's granulomatosis (Kanski, 2011).

Anterior uveitis is the most common form of uveitis. Features are typically with sudden onset of unilateral pain, photophobia and redness, which may be associated with lacrimation. Occasionally patients may notice mild ocular discomfort a few days before the acute attack when clinical signs are absent. Visual acuity is usually good. The presence of vitreal cells in an active vitritis are the main signs of pars planitis. Posterior uveitis encompasses retinitis, choroiditis and retinal vasculitis. Some lesions may originate primarily in the retina or choroid but often there is involvement of both (Sauberan, 2010).

Special investigations such as skin tests, serology and radiology are indicated in posterior uveitis, granulomatous inflammation, recurrent uveitis and bilateral uveitis.

Treatment of the majority of uveitis involves predominantly the use of anti-inflammatory and immunosuppressive agents. Antibiotic therapy for infectious diseases may be 
necessary. Topical steroids are the mainstay treatment for anterior uveitis, while systemic steroids are indicated in most cases of intermediate and posterior uveitis. If the disease is unresponsive to systemic steroids and/or the patient cannot tolerate systemic steroids, other immunosuppressive agents including azathioprine, methotrexate and ciclosporin may be used (Jancevski ,2010).

\section{Retinal detachment in children}

Retinal detachment is not common in infants and children. While the incidence of retinal detachment is 12 in 100000 in all age groups, only between $1.7 \%$ and $5.7 \%$ are diagnosed during childhood. The association of retinal detachment with complex intraocular pathologies in young children often presents a challenge to treatment.

There are 3 types of retinal detachment: Rhegmatogenous retinal detachment develops when there is a hole or tear in the retina, which transmits intraocular fluid underneath the retina and subsequent separation of the retina from the underlying pigment epithelium occurs. The second most common form is tractional, where the retina is pulled away from the underlying tissues. Exudative detachment develops when subretinal fluid accumulates under the retina such as in Coat's disease or vasoproliferative disorders (Yokoyama et al., 2004).

\subsection{Clinic and diagnosis}

Symptoms of retinal detachment are sudden onset of floaters, light flashes, appearance of black veil and loss of visual acuity. It is important to recognize that most of the small children cannot express loss of visual acuity and often vision may already be low due to concomitant ocular pathologies. Therefore the delay in diagnosis is more common in the pediatric retinal detachments compared to that in the adult retinal detachments. In a significant proportion of the patients, the diagnosis is made by chance during a routine eye examination or by noticing leukocoria. It is important to realize that retinal detachment in children may occur in both eyes frequently.

\subsection{Etiology}

Trauma has been reported to be the cause in $27-51 \%$ of cases of childhood retinal detachment. Ocular trauma is an important cause of retinal abnormalities in children and it is more common in boys. Retinal dialyses may be found in the superonasal or inferotemporal quadrant. Traumatic retinal detachment is seen most commonly in older children and is usually caused by blunt trauma (Sarrazin et al., 2004). The second frequent etiological factor is high myopia in children and if it is congenital may indicate an underlying abnormality. Retinal detachment may also result from intraocular infection or inflammation. The existence of systemic or hereditary diseases such as Trisomy 13 (Patau syndrome), Walker Warburg syndrome, Meckel syndrome, Norrie disease and incontinentia pigmenti should be investigated in retinal detachments of early childhood ( $0-1$ year). In such cases, central nervous system imaging and detailed neurological examination should be requested. Also it is important to rule out retinoblastoma. Some of these children do not live very long due to these systemic or hereditary diseases. Retinal detachment in infants and 
children should lead the physician to suspect a systemic disease, a syndrome, trauma, or a tumor in the eye. That should be ruled out with ultrasound or CT scan. Other causes of congenital or infantile retinal detachment should also be considered, including Stickler's syndrome, retinopathy of prematurity, persistent hyperplastic primary vitreous (PHPV), also called persistent fetal vasculature (PFV), may also present with a retinal detachment at birth; however, the associated microphthalmos and cataract often makes the diagnosis easier. Stickler's syndrome combines ocular, orthopedic and midfacial anomalies in an autosomal dominant inheritance pattern. Ocular abnormalities include high myopia, empty vitreous with membranes and bands.

\subsection{Management}

Prediction, prophylaxis and timely surgical treatment of retinal detachment may prevent visual loss. Retinal detachment in childhood and adolescence is different from adult cases due to higher rate of complicating predisposing factors such as trauma and high myopia and also due to the delay in the diagnosis that is mostly made after macular involvement. By appropriate surgical treatment the anatomic success rate may be as high as adult cases, however lower functional results are usually achieved because of higher rate of macular involvement (Butler et al., 2001; Topbas et al., 2003). It is important for the pediatrician to refer the children with signs and symptoms of retinal detachment, children with systemic disorders associated with retinal detachment and also children with ocular trauma history to an ophthalmologist.

\section{Retinoblastoma}

Retinoblastoma (RB) is the most common intraocular malignancy of the childhood, occurring in about in 1/15.000 to 20.000 live births. The tumor develops from the immature retina.

\subsection{Inheritance}

RB occurs in hereditary and nonhereditary forms. It can be unilateral or bilateral. The hereditary form is usually bilateral and multifocal, whereas the nonhereditary form is unilateral and unifocal. The RB gene is recognized to be a recessive suppresser gene located on chromosome 13 at the 13q14 segment and some affected children have other systemic features of the $13 \mathrm{q}$ deletion syndrome. It is accepted that all bilateral and familial cases of RB will manifest a germline mutation, whereas only $10-15 \%$ of unilateral sporadic cases will show germline mutation (Shields, 2006).

\subsection{Symptoms and diagnosis}

RB usually diagnosed between 3 months and 3 years of age, but it can be congenital or it can occur in older children. The affected child usually presents with leukocoria and/or strabismus. More advanced tumors can cause painful secondary glaucoma or signs of orbital cellulitis. The diagnosis of RB is best made by slit lamp bio-microscopy and indirect ophthalmoscopy. Ancillary studies are ultrasonography and computed tomography. The red-reflex examination is the best way to screen for retinoblastoma. 


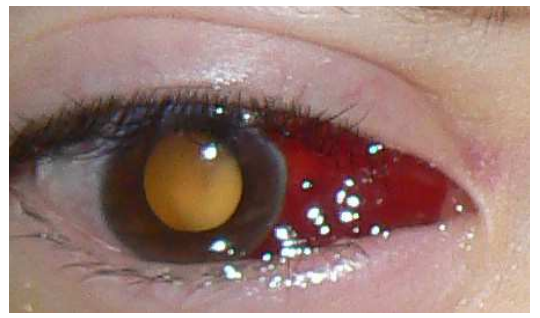

Fig. 8. Leukocoria due to RB

\subsection{Metastatic spread and second primary malignancies}

Metastatic spread is to regional nodes, lung, brain and bone. Second non-ocular cancers are leading cause of death in patients with the familial form of RB. Most common second tumors are soft tissue sarcoma, osteogenic sarcoma of the skull or the long bones, primitive neuroectodermal brain tumor and cutaneous melanoma. Trilateral RB refers to bilateral retinoblastoma associated with an intracranial primitive neuroectodermal tumor in the pineal or supraseller region (Murphree, 2006).

\subsection{Current management of RB}

Goals of treatment from most to least important ranking are: saving life, maintaining the eye and vision, and preserving cosmetic appearance. RB treatment typically requires the cooperation of an ophthalmic oncologist, pediatric oncologist and radiation therapist. Treatment varies depending on the number, size, and location of the tumors. Protocols are currently being evaluated to use chemoreduction therapy to shrink the RB in order to treat them with thermotherapy, laser therapy, cryotherapy, and local episcleral plaque radiation. More advanced tumors are managed by enucleation. External beam radiotherapy is typically reserved for eyes that fail the above methods, especially if retinoblastoma is bilateral. Lifelong monitoring is important to diagnose second primary tumor in the healthy eye as early as possible (Valenzuela, 2011).

\section{Systemic disease and eye in children}

\subsection{Intrauterine infections}

Congenital toxoplasmosis, cytomegalovirus, herpes simplex, lymphocytic choriomeningitis virus, varicella-zoster virus, West Nile virus infections are main intrauterine infections that may result in ocular pathologies. The principal ophthalmic manifestations are chorioretinal scar or an active chorioretinitis, and congenital cataract. When they are present in congenital toxoplasmosis, herpes simplex, and cytomegalovirus, they are associated with extensive eye involvement (Mets, MB. \& Kumar, 2006).

\subsection{Metabolic disease}

Disorders of copper metabolism: Wilson's disease. The principal ophthalmic manifestations are Kayser-Fleischer ring, due to copper deposition in Descemet's membrane and sunflower cataract. 
The mucopolysaaharidoses (Hurler syndrome, Schie syndrome, Hunter's syndrome, Sanfippo's syndrome): The principal ophthalmic manifestations are progressive corneal clouding, pigmentary retinal degeneration, optic atrophy, sometimes papilloedema and in certain cases glaucoma.

The gangliosidoses: Defects in lysosomal degradation of gangliosides can result in abnormal accumulation of these lipids. (Infantile, late infantile/Juvenile GM, Tay-Sachs disease) The principal ophthalmic manifestations are macular cherry red spot, tortiosity of retinal vessels, retinal hemorrhages and optic atrophy. Strabismus, nystagmus and mild corneal cloudy can be seen.

Niemann-Pick disease: The principal ophthalmic manifestations are macular cherry red spot, mild corneal haze and fine lens opacities.

Gaucher's disease: The principal ophthalmic manifestations are ocular lesions resembling pinguecula, paralytic strabismus and corneal opacities

Albinism: Genetic disorders of melanin synthesis. The principal ophthalmic manifestations are retinal hypopigmentation, foveal hypoplasia, misrouting of optic nerve fibers at the chiasm with altered visual function, iris hypopigmentation, photophobia, nystagmus, strabismus and high refractive errors.

Galactosemia: The principal ophthalmic manifestation is cataract (Martyn, 2006).

\subsection{Connective tissue disorders}

Angioid streaks (blood vessel-like) and visual loss may occur in pseudoxantoma elasticum

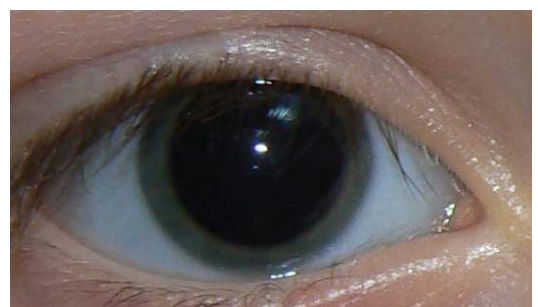

Fig. 9. Blue sclera in a case of EDS

Stretchable lids, retinal detachment and blue sclera have been reported in Ehler Danlos syndrome (EDS). Subluxation of crystalline lens, strabismus and retinal detachment may be seen in Marfan syndrome (Traboulski, 2006)

\section{Ocular trauma in children}

Ocular traumas in childhood are frequent and major causes of visual impairment, especially of unilateral non-congenital blindness in this age group. The frequency of eye traumas is almost double in boys especially in older age groups. This may be due to boys being more adventurous and aggressive. The $0-5$ years of age group was at greatest risk regardless of gender. 


\subsection{Evaluation}

Evaluation starts with a detailed history of the trauma, from the child if possible and also from the parents. Examination of the traumatized eye may be difficult in children. It is important to be patient and gentle. A mild sedative may sometimes be helpful. Visual function should be estimated in the beginning of the examination. Literate or illiterate Snellen charts may be used if possible. Otherwise reading any material or finger counting may help to determine the approximate level of visual acuity. Afterwards lids, conjunctivas and orbit are examined externally to reveal any lid lacerations or orbital rim fractures. The globe is examined carefully and gently. Irregular pupils, edema of the conjunctiva and blood in the anterior chamber and in the vitreous cavity are signs of severe ocular injury.

\subsection{Common eye injuries and management}

An external examination should be performed to look for eyelid lacerations which are seen as distortion of eyelids. A good functional and cosmetic result may only be obtained by appropriate suturing technique. Lacerations of the medial part of the lower lid may include lacrimal canaliculi. Tear drainage may be impaired leading to watering of the eye if not repaired properly.

Blunt ocular trauma may lead to traumatic hyphema, ruptured globe, retinal dialysis, retinal tears, macular hole and commosio retina. Hyphema is the collection of blood in the anterior chamber due to rupture of an iris or ciliary body vessel. Hyphema may be noticed as a red collection in the lower part of the anterior chamber or may fill the anterior chamber totally. Treatment includes bed rest, elevation of the head for approximately 45 degrees, cycloplegic and steroid eye drops. Blunt trauma may also rupture the eyeball. Conjunctival edema, soft eye and deep anterior chamber are signs of a posteriorly ruptured eye. Retinal tears and dialysis are severe consequences of blunt trauma which may lead to retinal detachment and therefore a detailed fundus examination is mandatory. Subretinal and intraocular hemorrhages may be highly associated with the shaken baby syndrome. Diffuse involvement of fundus with intravitreal and large subhyaloid hemorrhage are associated with more severe neurological injuries (MacEwen et al., 1999).

Corneal injuries may be in a spectrum from minor abrasions to serious penetrating wounds extending to the sclera. Abrasions are common and present with foreign body sensation, lacrimation and photophobia. It is important to look for a foreign body, which may be embedded at the upper tarsal conjunctiva, by everting the upper lid. Abrasions are treated by topical antibiotics and patching the eye. Irregular pupil due to iris prolapsus from the wound is a general finding of the penetrating injuries. If such an open globe injury is suspected, extreme care should be taken not to exert pressure to the globe and an eye shield should be placed over the eye. Systemic antibiotics, pain relievers and tetanus prophylaxis should be taken into consideration.

Chemical injuries may give damage to the eyelids, cornea and conjunctiva. Burns that penetrate deeper than the cornea are more serious and may lead to cataracts and glaucoma. Chemical injuries in children mostly occur at home from cleaning products or other regular household products. These injuries are dangerous and the treatment must be started 
immediately by irrigation with copious amounts of water as soon as possible. The type of injury, severity and the initial visual acuity are important prognostic factors for the final visual outcome. The visual prognosis is better if immediate diagnosis and treatment is provided and therefore it is important for the general physicians to recognize the severity of the trauma, provide suitable medical management and refer to the ophthalmologist as soon as possible (Moreira et al., 1988; Serrano et al., 2003).

\subsection{Prevention of eye injuries}

Most eye injuries can be avoided by simple measures, but still many children face serious visual impairment due to trauma. Most of the eye injuries occur at homes, in streets and roads, in schools and in other child care facilities. Adult supervision is an important factor for the prevention especially for the younger age groups. More than half of the injuries are without adult supervision at the time of event. Trauma is one of the most important preventable causes of blindness in children. Important points in prevention include parental supervision, education of children and protective eye-wears when necessary. Protective eye wears such as polycarbonate goggles should especially be recommended to functionally one eyed children (Mulvihill et al., 1997).

Recognition of eye injuries, taking immediate measures and referral to an ophthalmologist are key components in the management of eye injuries for general practitioners.

\section{References}

Allen, L. (2000). Pediatric eye examination, In: Pediatric Ophthalmology, Moore A,Lightman S. (eds), pp. 14-25, BMJ Books, ISBN 0-7279-1203-8, London

Astle, AT.; McGraw, PV. \& Webb, BS. (2011). Can Human Amblyopia be treated in Adulthood?. Strabismus, vol.19, no.3, (September 2011), pp. 99-109

Ballard EA. Excessive tearing in infancy and early childhood. (1925). The role and treatment of congenital nasolacrimal duct obstruction. Postgraduate medicine, vol.107, no.6, (May 2000), pp. 149-54, ISSN 0032-5481

Basmak, H.; Niyaz, L. \& Sahin A.; et al. (1991). Retinopathy of prematurity: screening guidelines need to be reevaluated for developing countries. European Journal of Ophthalmology, vol.20, no.4, (December 2009), pp. 752-55, ISSN 1120-6721

Butler, TK.; Kiel AW. \& Orr GM. (1917). Anatomical and visual outcome of retinal detachment surgery in children. Br J Ophthalmol, vol.85, no. 12, (December 2001), pp. 1437-1439, ISSN 0007-1161

Carlton, J. \& Kaltenthaler, E. (1987). Amblyopia and quality of life: a systematic review. Eye (Lond), vol.25, no.4, (April 2011), pp. 403-13, ISSN 1476-5454

Ciralsky, J. \& Colby, K. (1986). Congenital corneal opacities: a review with a focus on genetics. Semin Ophthalmol, vol.22, no.4, (October-December 2007), pp. 241-6, ISSN 0882-0538

Dale, RC.; Brilot, F. \& Banwell, B. Pediatric central nervous system inflammatory demyelination: acute disseminated encephalomyelitis, clinically isolated syndromes, neuromyelitis optica, and multiple sclerosis. (1993). Curr Opin Neurol, vol.22, no.3, (June 2009), pp. 233-240, ISSN 1350-7540 
Drack, AV. \& Kimura AE. (2006). Retinitis Pigmentosa and Associated Disorders, In: Handbook of Pediatric Retinal Disease, Wright, KW; Spiegel PH. \& Thompson LS. (Eds.), pp 135-177, Springer Science+Business Media, ISBN 10: 0-387-27932-6, USA.

Erol N. Treatment of Retinopathy of Prematurity. (2009). Türkiye Klinikleri Journal of Ophthalmology - Special Topics, vol.4, no.2, (July 2011), pp. 27-32, ISSN 1380-1160

Fredrick, DR. \& Asbury, T. (2004). Strabismus, In: General Ophthalmology, Riordan-Eva P. \& Whitcher JP. (eds), pp. 230-49, McGraw-Hill Companies, Inc, ISBN 0-07-137831-6, USA

Fredrick, DR. (2004). Special subjects of Pediatric Interest, In: General Ophthalmology,

Gilbert C. (1977). Retinopathy of prematurity: a global perspective of the epidemics, population of babies at risk and implications for control. Early Hum Dev, vol.84, no.2, (January 2008), pp. 77-82, ISSN 0378-3782

Goldstein, SM. \& Katowitz, JA. (2008). Infections of the eye and adnexa in children, In: Principles and Practice of Ophthalmology, Albert, DM. \& Miller, JW. (eds), pp. 4171-76, Elsevier, ISBN 978-1-4160-0016-7, Philadelphia

Harley, RD. Paralytic strabismus in children. Etiologic incidence and management of the third, fourth and sixth nerve palsies. Ophthalmology, vol.87, no.1, (January 1980), pp. 24-43, ISSN 0161-6420

Hughes, D. (2000). Eyelid disorders, In: Pediatric Ophthalmology, Moore, A. \& Lightman, S. (eds), pp. 154-61, BMJ Books, ISBN 0-7279-1203-8, London

Idrees, F.; Vaideanu, D. \& Fraser, SG.; et al. (1970).A review of anterior segment dysgeneses; Surv Ophthalmol, vol.51, no.3, (May 2006), pp. 213-31, ISSN 0039-6257

Jancevski, M. \& Foster, CS. (1990). Cataracts and uveitis. Curr Opin Ophthalmol, vol.21, no.1, (January 2010), pp.10-14, ISSN 1040-8738

Kanski, JJ. \& Bowling, B. (2011). Congenital cataract, In Clinical Ophthalmology: A Systematic approach, pp.298-304, Elsevier, ISBN-13:9780702040931, China

Kanski, JJ. \& Bowling, B. (2011). Cornea, In Clinical Ophthalmology: A Systematic approach, pp. 168-238, Elsevier, ISBN-13:9780702040931, China

Kanski, JJ. \& Bowling, B. (2011). Hereditary fundus dystrophies. In Clinical Ophthalmology: A Systematic approach. pp. 648-85, Elsevier, ISBN-13:9780702040931, China

Kanski, JJ. \& Bowling, B. (2011). Neuro-ophthalmology. In Clinical Ophthalmology: A Systematic approach. pp.789-812, Elsevier, ISBN-13:9780702040931, China

Kanski, JJ. \& Bowling, B. (2011). Orbit, In Clinical Ophthalmology: A Systematic approach, pp. 79-117, Elsevier, ISBN-13:9780702040931, China

Kanski, JJ. \& Bowling, B. (2011). Uveitis, In Clinical Ophthalmology: A Systematic approach, pp. 402-474, Elsevier, ISBN-13:9780702040931, China

Khani SC. \& Fasiuddin A. (2011). Generalized Inherited Retinal Dystrophies, In: Pediatric Retina, Reynolds, JD. \& Olitsky SE. (Eds.), pp. 295-303, Springer-Verlag, ISBN 978-3642- 12040-4, Berlin.

Kherani, F. \& Robb, RM. (2008). Congenital and developmental abnormalities of the eye, orbit, and ocular adnexa, In: Principles and Practice of Ophthalmology, Albert, DM. \& Miller, JW. (eds), pp. 4177-83, Elsevier, ISBN 978-1-4160-0016-7, Philadelphia

Krishnamurthy, R. \& Vanderveen, DK. (1961). Infantile cataracts. Int Ophthalmol Clin, vol.48, no.2, (Spring 2008), pp. 175-192, ISSN 0020-8167

Levin, AV. (1954). Congenital eye anomalies. Pediatr Clin North Am, vol.50, no.1, (February 2003), pp. 56-76, ISSN 0031-3955 
MacEwen, CJ.; Baines, PS. \& Desai, P. (1917). Eye injuries in children; the current picture. $\mathrm{Br}$ J Ophthalmol, vol.83, no.8, (August 1999), pp. 933-936, ISSN 0007-1161

Maida, JM.; Mathers, K. \& Alley, CL. (1990) Pediatric ophthalmology in the developing world. Curr opin Ophthalmol, vol.19, no.5, (September 2008), pp. 403-8, ISSN 10408738

Martyn, LJ. ( 2006). Metabolic disease, In : handbook of pediatrice ye end systemic disease. Wright, KW.; Spiegel, PH. \& Thompson, LS. (eds.), pp. 350-429. Springer, ISBN 10: 0-387-27927-X, China

Matta, NS.; Singman, EL. \& Silbert DI. (1951). Evidenced-based medicine: treatment for amblyopia. Am Orthopt J, vol.60, (November 2010), pp. 17-22, ISSN 0065-955X

Mets, MB. \& Kumar, AV. (2006). Eye Manifestations of Intrauterine Infections, In: Essentials in Ophthalmology: Pediatric Ophthalmology, Neuro-Ophthalmology, Genetics, Lorenz, B. \& Moore, AT. (Eds.), pp. 205-218. Springer-Verlag, ISSN 1612-3212, Berlin, Germany

Mickler, C.; Boden, J. \& Trivedi, RH.; et al. Pediatric cataract, Pediatr Ann, vol.40, no.2,(February 2011), pp. 83-87, ISSN 0090-4481

Mollon, JD.; Astell, S. \& Reffin, JP. (1991). A minimalist test of colour vision, In: Colour Vision Deficiencies, Drum B., Moreland JD. \& Serra A. (eds), pp. 59-67, Kluwer Academic Publishers, Dordrecht, ISBN 0-7506-4174-6, Netherlands

Moreira, CA., Jr.; Debert-Ribeiro, M. \& Belfort, R., Jr. (1960). Epidemiological study of eye injuries in Brazilian children. Arch Ophthalmol, vol.106, no.6, (June 1988), pp. 781784, ISSN 0003-9950

Morishita, H. \& Hensch, TK. (1991). Critical period revisited: impact on vision. Curr Opin Neurobiol, vol.18, no.1, (February 2008), pp. 101-7, ISSN 0959-4388

Mulvihill, A.; Bowell, R. \& Lanigan, B.; et al. (1995). Uniocular childhood blindness: a prospective study. J Pediatr Ophthalmol Strabismus, vol.34, no.2, (March April 1997), pp. 111-114, ISSN 0191-3913

Murphree, AL\& Christensen LE. (2006). Retinoblastoma and Other Malignant Intraocular

Mutti, DO. (1992). Hereditary and environmental contributions to emmetropization and myopia. Optom Vis Sci., vol.87, no4, (April 2010), pp.255-9, ISSN 1040-5488

Nicholson, B.; Ahmad, B. \& Sears, JE. (1961). Congenital optic nerve malformations. Int Ophthalmol Clin, vol.51, no.1, (Winter 2011), pp. 49-76, ISSN 0020-8167

Riordan-Eva P. (2004). Optics \& Refraction, In: General Ophthalmology, Riordan-Eva P. \& Whitcher JP. (eds), pp. 380-96, McGraw-Hill Companies, Inc, ISBN 0-07-137831-6, USA

Riordan-Eva, P. \& Whitcher, JP. (eds), pp. 353-62, McGraw-Hill Companies, Inc, ISBN 0-07137831-6, USA

Rose, G. (2000). Pediatric lacrimal and orbital disease. In: Pediatric Ophthalmology. Moore, A. \& Lightman, S. (eds), pp. 162-176, BMJ Books, ISBN 0-7279-1203-8, London

Sarrazin, L.; Averbukh, E. \& Halpert, M.; et al. (1884). Traumatic pediatric retinal detachment: a comparison between open and closed globe injuries. Am J Ophthalmol, vol.137, no.6, (June 2004), pp. 1042-1049, ISSN 0002-9394

Sauberan, DP. (1961). Pediatric uveitis. Int Ophthalmol Clin, vol.50, no.4, (Fall 2010), pp.7385,ISSN 0020-8167 
Serrano, JC; Chalela, P. \& Arias, JD. (1960). Epidemiology of childhood ocular trauma in a northestern Colombian region. Arch Ophthalmol, vol.121, no.10, (October 2003), pp. 1439-1445, ISSN 0003-9950

Shields, CL\& Shields JA. (2006). Pediatric Ocular Oncology, In: Essentials in Ophthalmology: Pediatric Ophthalmology, Neuro-Ophthalmology, Genetics, Lorenz B. \& Moore AT (Eds.), pp. 111-113. Springer-Verlag, ISSN 1612-3212, Berlin, Germany.

Sullivan, JH. (2004). Orbit, In: General Ophthalmology, Riordan-Eva P. \& Whitcher JP. (eds), pp. 250-60, McGraw-Hill Companies, Inc, ISBN 0-07-137831-6, USA

Topbas S, Toprak A, Erol N.; et al. Results of Conventional Retinal Detachment Surgery in Paediatric Age Group. Special Topic Issue: Ophthalmologica, vol. 214, no. 3, (2000), pp. 193, ISSN 0030-3755

Traboulski, EI. \& Martyn, LJ. ( 2006). Connective tissue, skin, and bone disorders, In : handbook of pediatrice ye end systemic disease. Wright, KW.; Spiegel, PH. \& Thompson, LS. (eds.), pp. 227-290. Springer, ISBN 10: 0-387-27927-X, China

Tumors, In: Handbook of Pediatric Retinal Disease, Wright, KW; Spiegel, PH. \& Thompson LS (Eds.), pp 246-283. Springer Science+Business Media, ISBN 10: 0-387-27932-6, USA .

Valenzuela, A; Chan, HSL. \& Heon, E; et al. (2011). A language for retinoblastoma: Guidelines and Standard operating procedures, In: Pediatric Retina, Reynolds, JD \& Olitsky, SE. (Eds.), pp. 205-234. Springer-Verlag, ISBN 978-3-642-12040-4, Berlin

Webber, AL. \&, Wood, J. (1969). Amblyopia: prevalence, natural history, functional effects and treatment. Clin Exp Optom, vol.88, no.6, (November 2005), pp. 365-75, ISSN 1444-0938

Yokoyama T.; Kato, T. \&, Minamoto, A.; et al. Characteristics and surgical outcomes of paediatric retinal detachment. Eye (London), vol.18, no.9, (September 2004), pp. 889892, ISSN 1476-5454 


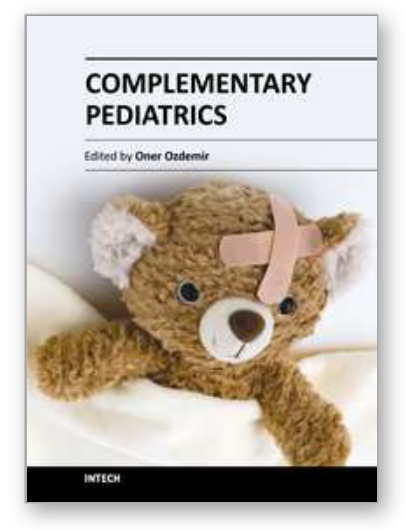

\author{
Complementary Pediatrics \\ Edited by Dr. Öner Özdemir
}

ISBN 978-953-51-0155-0

Hard cover, 354 pages

Publisher InTech

Published online 16, March, 2012

Published in print edition March, 2012

Complementary Pediatrics covers complementary issues of pediatric subspecialties consisting of ophthalmologic, surgical, psychosocial and administrative issues of frequently used medications. This book volume with its 16 chapters will help get us and patients enlightened with the new developments on these subspecialties' area.

\title{
How to reference
}

In order to correctly reference this scholarly work, feel free to copy and paste the following:

Hikmet Basmak, Nilgun Yildirim, Seyhan Topbas, Ahmet Ozer, Nazmiye Erol, Huseyin Gursoy and Afsun Sahin (2012). Pediatric Ophthalmology / Eye and Disorders, Complementary Pediatrics, Dr. Öner Özdemir (Ed.), ISBN: 978-953-51-0155-0, InTech, Available from: http://www.intechopen.com/books/complementarypediatrics/pediatric-ophthalmology-eye-and-disorders

\section{INTECH}

open science | open minds

\author{
InTech Europe \\ University Campus STeP Ri \\ Slavka Krautzeka 83/A \\ 51000 Rijeka, Croatia \\ Phone: +385 (51) 770447 \\ Fax: +385 (51) 686166 \\ www.intechopen.com
}

\author{
InTech China \\ Unit 405, Office Block, Hotel Equatorial Shanghai \\ No.65, Yan An Road (West), Shanghai, 200040, China \\ 中国上海市延安西路65号上海国际贵都大饭店办公楼 405 单元 \\ Phone: +86-21-62489820 \\ Fax: +86-21-62489821
}


(C) 2012 The Author(s). Licensee IntechOpen. This is an open access article distributed under the terms of the Creative Commons Attribution 3.0 License, which permits unrestricted use, distribution, and reproduction in any medium, provided the original work is properly cited. 